\title{
A NOVEL APPROACH TO CATALYTIC DESULFURIZATION OF COAL
}

\author{
Semi-Annual Technical Progress Report
}

Reporting Period:

September 1, 1999 - March 1, 2000

Principal Author:

John G. Verkade

IOWA STATE UNIVERSITY

Ames, IA 50011

Date Issued: October, 2000

\section{PREPARED FOR THE UNITED STATES DEPARTMENT OF ENERGY \\ Under Grant No. \\ DE-FG22-95PC95208}




\section{A Novel Approach to Catalytic Desulfurization of Coal}

DOE Grant No.: DE-FG22-95PC95208

Technical Report

Period Ending: 3/1/2000

Due Date: $3 / 31 / 2000$

Dr. John G. Verkade

Iowa State University

1275 Gilman Hall

Ames, Iowa 50011-2608

Phone: (515) 294-5023

E-mail: jverkade@iastate.edu

Abstract. A gas chromatographic method has been developed for the quantitation of sulfur removed from coal as tributyl phosphine sulfide $\left(\mathrm{SPBu}_{3}\right)$. This method also works very well for speciating and quantitating the products of sulfur removal from organosulfur removal from organosulfur compounds such as dibenzothiophene. Remarkably mild conditions have been discovered for quantitative sulfur removal from dibenzothiophene and other organosulfur systems using relatively cheap elemental sodium.

Project objectives.

A. Optimize the coal desulfurization reaction with respect to time, temperature, coal type

$$
\mathrm{Coal}(\mathrm{S})+\text { excess } \mathrm{PR}_{3} \longrightarrow \mathrm{Coal}+\mathrm{S}=\mathrm{PR}_{3} / \mathrm{PBu}_{3}
$$

and the $\mathrm{R}$ groups (including $\mathrm{R}=\mathrm{H}$ ), and also on extraction, impregnation and sonication conditions.

B. Optimize the conditions for the HDS reaction

$$
\mathrm{H}_{2}+\mathrm{S}=\mathrm{PR}_{3} \rightleftharpoons \mathrm{H}_{2} \mathrm{~S}+\mathrm{PR}_{3}
$$

(which allows the $\mathrm{PR}_{3}$ to function as an HDS catalyst for coal) with respect to $\mathrm{R}$ group, temperature pressure, $\mathrm{H}_{2}$ gas flow rate and inert solvent presence.

C. Determine the product(s) and the pathway of the novel redox reaction that appears to

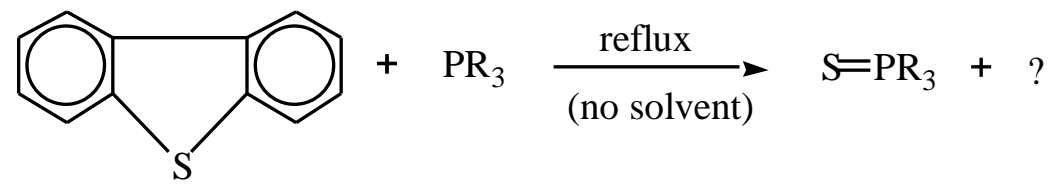


quantitatively remove sulfur from dibenzothiophene (DBT) when $\mathrm{R}=\mathrm{Bu}$ and when $\mathrm{FeCl}_{3}$ is used as a catalyst.

D. Impregnate sulfur-laden coals with $\mathrm{Fe}^{3+}$ to ascertain if the $\mathrm{PR}_{3}$ desulfurization rate increases.

E. Determine the nature of the presently unextractable phosphorus compounds formed in solid coals by $\mathrm{PR}_{3}$.

F. Explore the efficacy of $\mathrm{PR}_{3} / \mathrm{Fe}^{3+}$ in removing sulfur from petroleum feedstocks, heavy ends (whether solid or liquid), coal tar and discarded tire rubber.

G. Explore the possibility of using water-soluble $\mathrm{PR}_{3}$ compounds and $\mathrm{Fe}^{3+}$ to remove sulfur from petroleum feedstocks and heavy ends in order to remove the $\mathrm{SPR}_{3}$ (and $\mathrm{Fe}^{3+}$ catalyst) by water extraction (for subsequent $\mathrm{HDS}$ of the $\mathrm{SPR}_{3}$ ).

H. Explore the possibility of using solid-supported $\mathrm{PR}_{3}$ compounds (plus $\mathrm{Fe}^{3+}$ catalyst) to remove sulfur from petroleum feedstocks and heavy ends in order to keep the oil and the $\mathrm{SPR}_{3}$ (formed in the reaction) in easily separable phases.

\section{Background}

For environmental reasons, many efforts aimed at efficient desulfurization of coals have been made over the past two decades. Sulfur present in coals can be removed by physical, chemical, or microbial methods. ${ }^{1}$ The microbial process is slow but quite effective in removing all types of organic and inorganic sulfur simultaneously using a single type of bacterium. The simpler physical methods are currently more economical compared with processes that convert coal into liquid or gaseous fuels. Chemical processes developed in the past for the removal of both organically and inorganically bound sulfur from coal include the use of high temperature alkaline solutions, ${ }^{1}$ molten caustic at ca. $380^{\circ} \mathrm{C},{ }^{1 \mathrm{~d}}$ alkoxides in refluxing alcohol, ${ }^{1 \mathrm{e}} \mathrm{KOH}$ in supercritical alcohols, ${ }^{1 \mathrm{f}}$ oxidation with hydrogen peroxide ${ }^{2}$ and peroxyacetic acid, ${ }^{3}$ reductions involving hydrogenation,,${ }^{\mathrm{b}}$ carboxylation, ${ }^{4}$ zerovalent metal treatment, ${ }^{5}$ reactions with single-electron transfer agents, ${ }^{1 \mathrm{c}, 6}$ and strong base. ${ }^{7}$ Although these methods remove sulfur from coals to varying extents, other routes that improve coal desulfurization continue to be sought. Over the past decade, many organometallic systems 
have been investigated for their HDS properties and a substantial number of successful examples of C-S bond cleavage in benzothiophenes and dibenzothiophenes by such systems have been reported. ${ }^{8}$ In a recent patent from laboratory, ${ }^{9}$ data on the desulfurization of Illinois No. 6 coal with tributylphosphine under mild conditions were presented.

Here we report results bearing on Objective A and more specifically our further efforts to resolve the mass balance problem in reaction 1 . 
Results

We first describe the mass balance problem that continues to plague us. Arriving at a mass balance in these reactions has thus far not been successful. Reaction 1 as written is greatly oversimplified inasmuch as $\mathrm{Bu}_{3} \mathrm{P}$ is incorporated into the residue as its oxide, sulfide and protonated cation. Moreover, coal components are undoubtedly solubilized judging from the very dark coloration of the extract. Separation of the extract components has also not been achieved thus far. We considered the use of equation 2 wherein $\mathrm{M}=$ mass, $\mathrm{SM}=$ starting material, Res $=$ residue, and Rem $=$ removal.

$\% \mathrm{~S}_{\mathrm{Rem}}=\left(\frac{\mathrm{M}_{\mathrm{SM}} \mathrm{x} \% \mathrm{~S}_{\mathrm{SM}}-\mathrm{M}_{\mathrm{Res}} \mathrm{x} \% \mathrm{~S}_{\mathrm{Res}}}{\mathrm{M}_{\mathrm{SM}} \mathrm{x} \% \mathrm{~S}_{\mathrm{SM}}}\right) \times 100 \%$

Because $\mathrm{M}_{\text {Res }}$ does not simply represent the loss of coal components by reaction and/or solubilization, and because $\mathrm{M}_{\mathrm{Res}}$ can sometimes exceed $\mathrm{M}_{\mathrm{SM}}$ (see entry 7, Table 1), equation 2 is not warrented. We have thus opted at this time for equation 3, which disregards $\% \mathrm{~S}$ removal $=\left(\frac{\% \mathrm{~S}_{\mathrm{SM}}-\% \mathrm{~S}_{\mathrm{RES}}}{\% \mathrm{~S}_{\mathrm{SM}}}\right) \times 100 \%$

the mass changes that have occurred. It may be noted that in most equation 3 by $1-23 \%$, thus

To attack this problem, we have designed an apparatus that will allow us to perform accurate mass balances, as well as expose the coal sample to fresh $\mathrm{Bu}_{3} \mathrm{P}$ throughout the extraction run. The design we have developed is similar to that of a Soxhlet apparatus, but its appearance and function is quite different. The problem with the Soxhlet apparatus is that there is considerable hang-up of an extractant by adsorption on all the surfaces above the liquid, including the extraction chamber and the inside of the reflux condenser. The Soxhlet cup also retains considerable $\mathrm{Bu}_{3} \mathrm{P}$ by absorption into the fibrous cup material. It is 
unfeasible to weigh the adsorbed and absorbed $\mathrm{Bu}_{3} \mathrm{P}$ in the apparatus because its mass is small relative to that of the apparatus and the cup containing the extracted coal, respectively.

Our apparatus design in Figure 1 (which greatly minimizes glass surface) consists of a $50 \mathrm{~mL}$ flask fitted with a small water-cooled cold finger at the end of which is suspended an "envelope" created from filter paper. The envelope contains the weighed coal sample to be extracted. Several grams of $\mathrm{Bu}_{3} \mathrm{P}$ is accurately weighed into the flask via a syringe and reflux is carried out at $250^{\circ} \mathrm{C}$. The cold finger condenses the $\mathrm{Bu}_{3} \mathrm{P}$ and allows the hot condensate to wash through the filter paper. The conditions are controlled such that the condensate is very nearly $250^{\circ} \mathrm{C}$. At the end of the run, the flask is allowed to cool to room temperature. The hang-up of $\mathrm{Bu}_{3} \mathrm{P}$ on the relatively small amount of glass surface is calculated to be small compared with the original mass of liquid whose total volume we calculate from its density. (Accumulation of a drop of $\mathrm{Bu}_{3} \mathrm{P}$ at the end of the cold finger is prevented by connection of the cold finger end to the filter paper holding the sample). After a volumetric aliquot of extract is withdrawn and weighed in a syringe, we can calculate the new density of the extract and also calculate quite precisely how much mass the coal has lost by extraction, realizing that a corrected mass must be calculated for the amount of $\mathrm{Bu}_{3} \mathrm{P}$ trapped in the coal residues, and an extract density correction must be made for the $\mathrm{Bu}_{3} \mathrm{P}$ in the filter paper. The former can be done by phosphorus elemental analysis of the extracted coal sample, and the latter correction can be accomplished as follows. The filter paper containing the extracted sample is transferred to a clean apparatus of the same design and washed with refluxing ether. The filter paper envelope is then dried and weighed to gauge the coal mass loss which is then compared with that calculated from the mass gain of the extract. Sulfur elemental analyses on both the extract and the extracted residue can then be compared and used as checks on the accuracy of the sulfur elemental analysis. All of the manipulations must be carried out under nitrogen or argon to prevent oxidation of $\mathrm{Bu}_{3} \mathrm{P}$. 
A potential complication of the calculated sulfur removal might be the sulfur that is trapped in the residue as $\mathrm{Bu}_{3} \mathrm{P}=\mathrm{S}$ (which is detectable by CP MAS ${ }^{31} \mathrm{P}$ NMR spectroscopy). We believe this will now be a negligible problem because of constant exposure of the sample to pure hot condensed $\mathrm{Bu}_{3} \mathrm{P}$ that will wash out the $\mathrm{Bu}_{3} \mathrm{P}=\mathrm{S}$ much more completely. Thus in our sealed tube experiments described in the previous report, a mixture of extract (containing dissolved $\mathrm{Bu}_{3} \mathrm{P}=\mathrm{S}$ ) and coal residue is present throughout the run which allows an equilibrium to be established between $\mathrm{Bu}_{3} \mathrm{P}=\mathrm{S}$ dissolved in the extract and trapped in the coal.

By solving the mass balance problem, we will be more confident that there is fascinating, but puzzling, chemistry that goes on in the coal matrix that we are unable to duplicate outside of the matrix with thiophene compounds. That is, pure thiophenes in refluxing $\mathrm{Bu}_{3} \mathrm{P}$ do not lose significant amounts of sulfur regardless of the presence of a variety of metal ions and/or $\mathrm{HPBu}_{3}{ }^{+}$and/or a catalytic amount of coal.

Dr. Guangtao Zhang, a postdoctoral student in my group carried out a series of experiments with the apparatus shown in Figure 1. He found, however, that unfortunately the degree of sulfur extraction was variable and poor. The problem is that the temperature of the tributylphosphine passing through the coal inside the filter paper is actually considerably below $250^{\circ} \mathrm{C}$ owing to the fact that the reflux finger cools the refluxing tributylphosphine too greatly, even when no coolant is allowed to flow through the finger. Thus the envelope and its contents is unable to reach $250^{\circ} \mathrm{C}$, the temperature at which the extraction efficiency is highest according to the results described in our previous reports.

It should be pointed out that it is also very difficult to control the level of the reflux line in the apparatus while still maintaining a liquid flow through the envelope at a sufficiently high temperature for extraction. There appears to be too much conduction of heat away from the filter paper/coal and too little flow of tributylphosphine through the coal. 
Thus most of the liquid extractant contact seems to flow over the outside of the envelope. Most of the tributylphosphine seems to run over the outside of the envelope. We believe we can solve this problem by using tea bag cloth, which is more porous and will hopefully still retain the powdered coal if the mesh is not too fine. These experiments will be carried out by Dr. Xiadong Liu in the remaining period of this grant.

References

1. (a) Wheelock, T. D. “Coal Desulfurization-Chemical and Physical Methods” American Chemical Society, Washington, DC, 1977. (b) Wheelock, T.D.; Markuszewski, R. "The Science and Technology of Coal and Coal Utilization”, Cooper, B. R.; Ellingson, W. A. (Eds.), Plenum Press, New York, 1984. (c) Speight, J. G. “The Chemistry and Technology of Coal”, $2^{\text {nd }}$ Edition, Marcel Dekker, Inc., New York, 1994. (d) Calkins, W. H. Fuel, 1994, 73, 475. (e) Mazumdar, B.; Saika, P. C.; Sain, B.; Baruah, B. P.; Borodoloi, C. S. Fuel 1989, 68, 810. (f) Stock, L. M. Prepr. Pap.-Am. Chem. Soc., Div. Fuel Chem. 1994, 39, 74.

2. Ali, A.; Srivastava, S. K.; Haque, R. Fuel 1992, 71, 835.

3. Palmer, S. R.; Hippo, E. J.; Dorai, X. A. Proceedings of the Ninth Annual International Pittsburgh Coal Conference, 1992, 77.

4. Duty, R. C.; Penrod, J. M. Energy \& Fuels, 1994, 8, 234.

5. (a) Buchanan, D. H. in "Qtrly. Rpt. Of Center for Research on Sulfur in Coal", May 31,1991. (b) Handrick, K.; Koelling, G. Proc. Int. Conf. Coal. Sci. 1983, 334.

6. (a) Catterjee, K.; Stock, L. M. Energy \& Fuels, 1990, 4, 402. (b) Buchanan, D. H.; Kalembasa, S.; Olson, D.; Wang, S.; Warfel, I. Report 1991, DOE/90176-T63, Energy, Res. Abstr. 1992, 17, 6189. 
7. Chatterjee, K.; Stock, L. M. Energy \& Fuels, 1991, 5, 704.

8. (a) Matsubara, K.; Obamura, R.; Tanaba, M.; Suzuki, H., J. J. Am. Chem. Soc. 1998, 120, 1108 and references therein. (b) Vicic, D. A.; Jones, W. D. J. Am. Chem. Soc. 1997, 119, 10855.

9. Verkade, J. G.; Mohan, T. US Patent, 5,509,0945. 
Summary of Progress. We have developed a reliable analytical method for the analysis of the sulfur removed from coal using tributyl phosphine, $\mathrm{Pbu}_{3}$ (see reaction 1 in Objective A and, more specifically reaction 4 below). The method involves gas chromatographic (gc) analysis

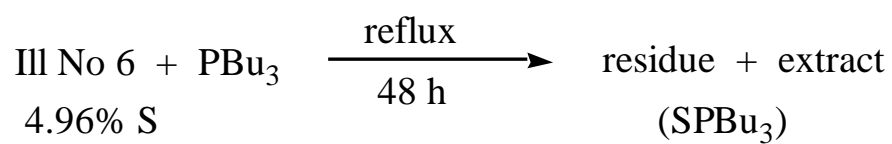

of the $\mathrm{SPBu}_{3}$ in the extract. Using this approach combined with elemental analysis for sulfur of both the residue and the extract, up to ca $90 \%$ of the sulfur can be removed from the coal. Using gc analysis we have discovered that elemental sodium (which is about five times cheaper per mole than $\mathrm{PBu}_{3}$ ) cleanly removes sulfur from dibenzothiophene, DBT (and other organic sulfur compounds) under very mild conditions (reaction 5). We have also made the

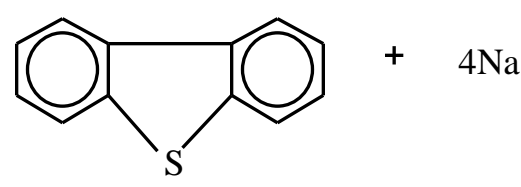

DBT

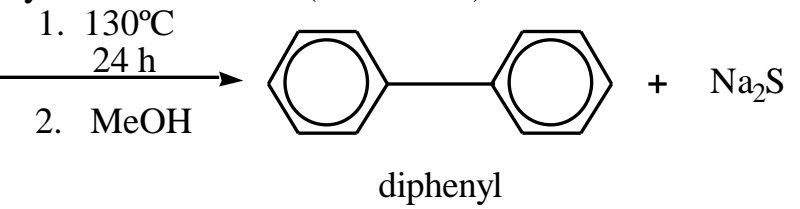

rather exciting discovery that benzothiophene (BT) loses $100 \%$ of its sulfur to elemental sodium in only 6 hours when the reaction is carried out in liquid ammonia at $-\mathbf{3 8}^{\circ} \mathrm{C}$ (reaction $6)$ !

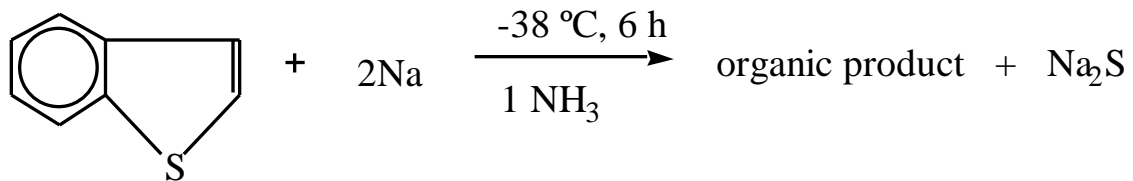

Amoco recently sent us a petroleum distillate sample that contains less than $1 \%$ organic sulfur. If we can successfully remove the sulfur, Amoco would like to support our research efforts. If the economics are favorable, the process could become commercial.

A recent Aldrich Chemical Co. catalog lists the compound below as a ${ }^{31} \mathrm{P}$ NMR derivatizing agent for speciating and quantitating mixtures of alcohols. The catalog cites our publication in which we describe its usefulness for these purposes in analyzing phenols in CONSOL coal liquefaction samples.

Results. We have found that the ${ }^{31} \mathrm{P} \mathrm{NMR}$ analyses of sulfur as $\mathrm{SPBu}_{3}$ in coal extracts are unreliable. Thus ratios of peak integrations for $\mathrm{PBu}_{3} / \mathrm{SPBu}_{3}$ were at variance with elemental analyses. Part of this problem could be attributed to the presence of paramagnetic mineral materials extracted from the coal that broaden the NMR peaks thus interfering with quantitation of the peak areas. Quantitatively separating $\mathrm{PBu}_{3}$ from $\mathrm{SPBu}_{3}$ by column chromatography also failed. Attempts to remove $\mathrm{PBu}_{3}$ cleanly from the extract via reaction 7 were also not successful. Following several other attempts to quantitate sulfur removal from coal and form organosulfur compounds, as well as additional experiments to speciate and quantitate extracted materials, we have finally developed a satisfactory method. Part of the reason for the success of the method is that it employs a guard column for the gc in order to remove metal species (extracted from the coal) that would damage the gc column. Our technique has proven to be the method of choice for a number of reasons that will become evident later in this report. 